\title{
Community psychiatry at the National Institute of Mental Health and Neuro Sciences, India
}

\author{
Easier than working in Manchester
}

\author{
Tom Burns
}

A Lundbeck visiting professorship organised through the Royal College of Psychiatrists gave me the opportunity to spend three weeks, in January 1996, at the National Institute of Mental Health and Neuro Sciences (NIMHANS) in Bangalore, India as the guest of Professor Srinivasa Murthy. NIMHANS has an international reputation as a centre for training and research in psychiatry, including an innovative approach to community psychiatry. For this work they are justifiably renowned and are a World Health Organization (WHO) collaborating site (Goldberg, 1992; Isaac, 1996). As well as producing training manuals for mental health workers from the developing world their outreach model has been exported to several countries.

For a psychiatric observer there is much to report from such a complex society. The staggering variations between people (linguistic, racial, cultural, spiritual, financial) made mental illness less obvious and stigmatising. The experience on the wards, and in out-patients, of a generally calm, ordered atmosphere despite the severity of the disorders was striking. I was left with a vivid understanding of the previously perplexing observation of a better outcome for schizophrenia in the developing world, reported by the 'International Pilot Study on Schizophrenia' (Jablensky et al, 1992; Leff et al, 1992). Evidence of the protective effects of family supports and obligations was omnipresent. Junior doctors who had worked in the UK commented on how much less threatened by potential violence or assault they felt in India. Despite limited resources and the vast pressure of numbers they felt less personally burdened - patients and families expected advice about their illnesses but did not expect the doctor to shoulder the responsibility. Commenting on the unrealistic expectations which burdened them when working in the UK two registrars independently joked that "it was easier than working in Manchester."
During my time I was able to see three different approaches to community psychiatry operated out of NIMHANS. The first was an outreach clinic, common in much of the developing world. four of which were established by NIMHANS 15 years ago. The second was a model community development run by NIMHANS in Saklavara which has been developing for several years both as a demonstration service and as a base for epidemiological research (Channabasavanna et al, 1996). The third was the first attempt to export a NIMHANS public health, community psychiatry service to the geographically distant area of Bellary and see if it could survive without continuing support.

\section{Gorbidanaur outreach camp}

The monthly outreach clinic (referred to as a 'camp') that I attended was two bone-shaking hours travel by NIMHANS minibus. There were two psychiatrists, one social worker, two nurses, one clinical psychologist, two pharmacists and two medical record clerks. The gynaecological ward of a local hospital was cleared for the day. NIMHANS insists on local commitment to these services to ensure their durability so drug costs were met by local voluntary groups and the local sugar factory provided our lunch.

The clinic has two functions - as a pharmacy for free repeat prescriptions (which can only be dispensed monthly) and as an out-patient department for new assessments and reviews. Repeat prescriptions were dealt with directly by the pharmacists but all patients are reviewed every three months (or if there is any problem) by a mental health professional. About $65 \%$ of attendances were for epilepsy. Substantial numbers of patients with neurological disorders presented at all clinics I attended. Psychiatrists saw this as a core part of their role and were 
both confident and comfortable in treating neurological patients. Patients were invariably accompanied by a relative and often the relative came as a proxy to collect medicines.

Eight hundred and seventy patients attended this clinic! Forty-eight were new. New patients were clerked by the social workers, psychologists or nurses and then examined by a doctor. An impressive feature of NIMHANS is that registrars. clinical psychologists and social workers share much of their two-year postgraduate training programme. This includes the same basic model of history taking (introduced by Meyer Gross in the 1950s) and I was struck by the uniformly high standard of histories and presentations. Having some shared postgraduate training also seems to have contributed to smoother interdisciplinary relations, perhaps something to explore in the UK? The staff member chosen for a patient was often one who knew the relevant language (at least five were being used). Communication between professionals was exclusively in English.

Fits in children were the most common new presentations and we saw a number of severely learning disabled children and several severely physically ill patients. Over a dozen patients with schizophrenia appeared to be responding well to chlorpromazine. Two anxious middle-aged women presented with severe somatisation and were treated with tricyclics, and only one patient was openly distressed in the clinic. Kishore Kumar had been involved in developing the structured assessment and follow-up notes used in this clinic and maintained on a computer database for the past three years. Each patient had one folded A4 sheet and there was a forced choice of the common groups of disorders with some space for free text and follow-up notes. Patients held their own medication records in small plastic bound booklets.

The clinic fostered a strong team spirit. That the psychiatric tasks were not particularly complex or challenging was compensated for by a genuine sense of achievement.

\section{Saklawara Mental Health Centre}

Saklawara Mental Health Centre is $20 \mathrm{~km}$ from Bangalore and serves an immediate population of $\mathbf{3 0 0 0 0}$ but draws from a wider area of about 30 miles. Its full-time general practitioners had six observation beds and it was developed to demonstrate the integration of mental health and general health care services. There are daily clinics in the centre for psychiatric and general patients and peripheral weekly clinics (each attended by about 200 patients) for the surrounding district of 150000 . In these clinics everyone is seen by a mental health worker not only a pharmacist. Depressed and neurotic patients were more evident in this clinic.

Kishore Kumar, a dedicated full-time community psychiatrist, had worked in Saklawara for five years and took me on several home visits of which the following is illustrative.

Krishna, a man of 42 with a history of repeated paranoid schizophrenic episodes since his early 20s, had one eight day admission to NIMHANS during his first breakdown. He was warm and engaging in his conversation and had worked full time in a factory job until made redundant four years ago. He now works as a dairy man for his father who lives next door. He married in his late 20 s and has three children. He receives fluphenazine $25 \mathrm{mg}$ monthly and regular anticholingergics. He had tried to stop his medication a few times but promptly relapsed each time. He does not really think that he is mentally ill, just that his neighbours occasionally try to get at him and he hears threatening voices and feels strange forces.

His wife had no idea he had been ill when she married him, had she known she would have refused but now accepted her lot. She could not understand why he did not trust her when he was ill, but was happy that their children were doing well at school and they were a devout Hindu family. The father also joined us and was clearly still the boss. He said that his son's illness was sad but denied that it was a shame on the family. He cited three successful marriages in the close family as evidence that they were not burdened by stigma. Dr Kumar's approach was to relate to the whole family as a unit and to lend support to their decision-making rather than impose goals for management.

\section{Bellary District Service}

Bellary in northern Karnataka with a population of 1.9 million, was chosen by NIMHANS to pilot their community mental health services. The policy of integrating fully with primary care had worked successfully in Saklawara and now it was to be tried across a whole district and without NIMHANS staff. The initiative started with a series of three-day courses to teach primary care physicians about mental health. From this Dr Karur was recruited, he completed a two year Diploma in Psychological Medicine at NIMHANS and returned as project manager for mental health. Primary care in India has a strong public health ethos emphasising local targets in specific 'projects' (such as immunisation, malaria monitoring, maternal and child health etc). 
Mental health was added as a project for Bellary in 1988 and is now being introduced within other states in India.

Dr Karur's job has three main parts. He holds a specialist psychiatric clinic in Bellary three afternoons a week. To avoid de-skilling he refers patients back to their primary care centres for ongoing treatment. He acknowledged the professional temptation to become increasingly specialised, which, although personally rewarding was not in the wider patients' interests.

His second role is as liaison psychiatrist to the local general hospital and while I was with him a frail, terrifled woman hiding her face in her sari was brought over from the medical wards. She was clearly toxic with a pulse over 120. Dr Karur welcomed the referral as evidence that the residents were considering psychological issues.

Dr Karur's main role as mental health project director for the whole district involves him negotiating targets and monitoring achievement. Targets are set in terms of the detection and treatment rates for psychosis and epilepsy. He regularly visits and audits the practice of the primary care centres in his district. Dr Karur advises on difficult cases (e.g. a complex interaction of epilepsy and alcohol misuse) while encouraging and supporting local competence.

Primary care physicians were left in no doubt that this part of their work was important and that Dr Karur took it, and them, seriously. He required monthly reports on progress, conducted random checks of the simple, structured case notes for their adequacy and accuracy (he was adept at spotting bogus entries, usually betrayed by unusual regularity) and discussed targets and figures. There is a major problem of morale in the service and great difficulty of retention of doctors overall in relatively poorly paid Government, academic and rural posts. This was exacerbated by an over-prescriptive career structure and central bureaucracy.

Dr Karur had been in post for over seven years and for the first five of these had received regular and intensive support from Professor Mohan Isaac. The viability of the service without that support was now being tested. Professor Isaac's visit with me was his first since withdrawing support and was encouraging. Dr Karur had maintained his enthusiasm and the district was keeping up its detection rate of new psychoses at between 200-400 per annum.

I was impressed with the system, a rigorously targeted approach with realistic and humane, clinically relevant procedures and monitoring. Such a highly structured format is clearly needed to ensure that sparse public resources reach the needy in the vast, uncomplaining Indian poor. How enduring it will be remains to be seen. Despite the clarity and strength of the model I was struck by the outstanding skills and commitment of the key people in NIMHANS and Bellary. It is no accident that they are leading these remarkable innovations. Replicating the achievements of innovators is notoriously diffcult in community psychiatry! More threatening. however, was the spirit of radical change in India generally. Economic boom in the commercial centres, accelerating deregulation and disenchantment with central planning is going to make it very difficult to keep good quality doctors away from private practice and in poorly paid rural posts.

NIMHANS community psychiatry services combined an exhilarating mix of pragmatism. inter-professional collaboration and respect for a wide range of theoretical frameworks and professional perspectives. The need to be explicit about the values of the service was driven by the obvious ethical issues surrounding rationing of care. Far from constricting thinking (as I had anticipated) this frank acknowledgement of the social construction of health priorities fostered an open-minded atmosphere which made NIMHANS scientifically productive and genuinely imaginative. Certainly a place to visit for both professional and personal learning (Burns, 1997).

\section{Acknowledgements}

I thank my three generous hosts. Professor Srinivasa Murthy. Professor Mohan Isaac and Dr Kishore Kumar, for their attentiveness during my four week stay at NIMHANS. Funding for the visit was provided to the Royal College of Psychiatrists by a grant from the Lundbeck Foundation.

\section{References}

BURNS. T. (1997) Letting the job get to you. British Medical Journal, 314. 727.

Channabasavanna, S. M., Sriramm, T. G. \& Kumar, K. (1996) Results from the Bangalor Centre. In Mental Illness in General Health Care (eds T.B. Ustun \& N. Sartorius). pp. 79-96. Chichester: John Wiley and Sons.

GolDBERG, D. (1992) India, Pakistan: Community Psychiatry. Lancet, 1. 114-115.

ISAAC, M. (1996) Trends in the development of psychiatric services in India. Psychiatric Bulletin, 20, 43-45.

JABLENSKY, A., SARTORIUS, N.. ERNBERG, G.. et al (1992) Schizophrenia: Manifestations. Incidence and Course in Different Cultures. A World Health Organization TenCountry Study. Psychological Medicine, Monograph Supplement 20. Cambridge: Cambridge University Press.

LEFF, J., SARTORIUS, N.. JABLENSKY, A., et al (1992) The international pilot study of schizophrenia: five-year follow-up findings. Psychological Medicine. 22. 131-145.

Tom Burns, Head of the Community Psychiatry Section Department of General Psychiatry. St George's Hospital Medical School, Jenner Wing. Cranmer Terrace, London SW17 ORE 